\title{
Mucosal-associated invariant T cell alterations during the development of human type 1 diabetes
}

\author{
Ahmad M. Gazali ${ }^{1,2}$ (D) Anna-Mari Schroderus ${ }^{1}$ (D) Kirsti Näntö-Salonen $^{3}$ (D) Reeta Rintamäki $^{4}$. \\ Jussi Pihlajamäki $^{5,6}$ (D) Mikael Knip ${ }^{7,8,9,10}$ (D) $\cdot$ Riitta Veijola $^{11}$ (D) Jorma Toppari ${ }^{3,12}$ (D) $\cdot$ Jorma Ilonen $^{13,14}$ (D) \\ Tuure Kinnunen $^{1,15}$ (D)
}

Received: 20 May 2020 / Accepted: 14 July 2020 / Published online: 3 September 2020

(C) The Author(s) 2020

\begin{abstract}
Aims/hypothesis Mucosal-associated invariant T (MAIT) cells are innate-like T cells that recognise derivatives of bacterial riboflavin metabolites presented by MHC-Ib-related protein 1 (MR1) molecules and are important effector cells for mucosal immunity. Their development can be influenced by the intestinal microbiome. Since the development of type 1 diabetes has been associated with changes in the gut microbiome, this can be hypothesised to lead to alterations in circulating MAIT cells. Accordingly, peripheral blood MAIT cell alterations have been reported previously in patients with type 1 diabetes. However, a comprehensive analysis of the frequency and phenotype of circulating MAIT cells at different stages of type 1 diabetes progression is currently lacking.

Methods We analysed the frequency, phenotype and functionality of peripheral blood MAIT cells, as well as $\gamma \delta \mathrm{T}$ cells, invariant natural killer T (iNKT) cells and natural killer (NK) cells with flow cytometry in a cross-sectional paediatric cohort (aged 2-15) consisting of 51 children with newly diagnosed type 1 diabetes, 27 autoantibody-positive ( $\mathrm{AAb}^{+}$) at-risk children, and 113 healthy control children of similar age and HLA class II background. The frequency of MAIT cells was also assessed in a separate crosssectional adult cohort (aged 19-39) of 33 adults with established type 1 diabetes and 37 healthy individuals of similar age.

Results Children with newly diagnosed type 1 diabetes displayed a proportional increase of CD8 ${ }^{-}$CD2 $7^{-}$MAIT cells compared with healthy control children (median $4.6 \%$ vs $3.1 \%$ of MAIT cells, respectively, $p=0.004$ ), which was associated with reduced expression of C-C chemokine receptor (CCR) 5 (median $90.0 \%$ vs $94.3 \%$ of MAIT cells, $p=0.02$ ) and $\beta 7$ integrin (median $73.5 \%$ vs $81.7 \%$ of MAIT cells, $p=0.004$ ), as well as decreased production of IFN- $\gamma$ (median $57.1 \%$ vs $69.3 \%$ of MAIT cells,
\end{abstract}

Electronic supplementary material The online version of this article (https://doi.org/10.1007/s00125-020-05257-7) contains peer-reviewed but unedited supplementary material, which is available to authorised users.

Tuure Kinnunen tuure.kinnunen@uef.fi

1 Department of Clinical Microbiology, Institute of Clinical Medicine, University of Eastern Finland, Kuopio, Finland

2 Present address: Faculty of Industrial Sciences and Technology, Universiti Malaysia Pahang, Pahang, Malaysia

3 Department of Pediatrics, Turku University Hospital, Turku, Finland

4 Department of Medicine, Kuopio University Hospital, Kuopio, Finland

5 Institute of Public Health and Clinical Nutrition, University of Eastern Finland, Kuopio, Finland

6 Clinical Nutrition and Obesity Center, Kuopio University Hospital, Kuopio, Finland

7 Tampere Center for Child Health Research, Tampere University Hospital, Tampere, Finland
8 Children's Hospital, University of Helsinki and Helsinki University Hospital, Helsinki, Finland

$9 \quad$ Research Program for Clinical and Molecular Metabolism, Faculty of Medicine, University of Helsinki, Helsinki, Finland

10 Folkhälsan Research Center, Helsinki, Finland

11 PEDEGO Research Unit, Department of Pediatrics, Medical Research Center, Oulu University Hospital and University of Oulu, Oulu, Finland

12 Institute of Biomedicine, Research Centre for Integrative Physiology and Pharmacology, University of Turku, Turku, Finland

13 Immunogenetics Laboratory, Institute of Biomedicine, University of Turku, Turku, Finland

14 Clinical Microbiology, Turku University Hospital, Turku, Finland

15 Eastern Finland Laboratory Centre (ISLAB), Kuopio, Finland 


\section{Research in context}

\section{What is already known about this subject?}

- Decrease in gut microbiota diversity and intestinal dysbiosis have been reported both in patients with type 1 diabetes and in autoantibody-positive individuals at risk for type 1 diabetes

- The intestinal microbiome affects the development of mucosal-associated invariant T (MAIT) cells

- Three previous studies have reported alterations in circulating MAIT cells in patients with type 1 diabetes and autoantibody-positive at-risk individuals

What is the key question?

- $\quad$ Are there changes in circulating MAIT cell frequency and/or phenotype at different stages of type 1 diabetes progression?

\section{What are the new findings?}

- In children with newly diagnosed type 1 diabetes, a larger fraction of circulating MAIT cells displayed a CD8 ${ }^{-}$CD27phenotype, with reduced expression of CCR5 and $\beta 7$ integrin, as well as decreased production of IFN- $\gamma$ by the cells, compared with healthy children

- In autoantibody-positive at-risk children who later progressed to type 1 diabetes and in adult patients with a short duration of type 1 diabetes, the frequency of circulating MAIT cells was decreased compared with healthy individuals of a similar age

\section{How might this impact on clinical practice in the foreseeable future?}

- Decrease in frequency and functional alteration of peripheral blood MAIT cells appear to be temporally associated with the onset of clinical type 1 diabetes, potentially implicating them in the disease process

$p=0.04)$ by the MAIT cells. The frequency of MAIT cells was also decreased in $\mathrm{AAb}^{+}$children who later progressed to type 1 diabetes compared with healthy control children (median $0.44 \%$ vs $0.96 \%$ of $\mathrm{CD}^{+} \mathrm{T}$ cells, $p=0.04$ ), as well as in adult patients with a short duration of type 1 diabetes (less than 6 years after diagnosis) compared with control individuals (median $0.87 \%$ vs $2.19 \%$ of $\mathrm{CD}^{+} \mathrm{T}$ cells, $\left.p=0.007\right)$. No alterations in $\gamma \delta \mathrm{T}$ cell, iNKT cell or NK cell frequencies were observed in children with type 1 diabetes or in $\mathrm{AAb}^{+}$children, with the exception of an increased frequency of IL-17A ${ }^{+} \gamma \delta \mathrm{T}$ cells in children with newly diagnosed diabetes compared with healthy control children (median $1.58 \%$ vs $1.09 \%$ of $\gamma \delta \mathrm{T}$ cells, $p=0.002$ ).

Conclusions/interpretation Changes in the frequency and phenotype of circulating MAIT cells were detectable before, at the onset and after diagnosis of type 1 diabetes in cross-sectional cohorts. Our results suggest a possible temporal association between peripheral blood MAIT cell alterations and the clinical onset of type 1 diabetes.

Keywords Autoimmunity $\cdot$ Human $\cdot$ Immunophenotyping $\cdot$ MAIT cells $\cdot$ Mucosal immunity $\cdot$ T cells $\cdot$ Type 1 diabetes

$\begin{array}{ll}\text { Abbreviations } \\ \mathrm{AAb}^{+} & \text {Autoantibody-positive } \\ \mathrm{CCR} & \text { C-C chemokine receptor } \\ \mathrm{DN} & \text { Double negative } \\ \mathrm{DP} & \text { Double positive } \\ \mathrm{IBD} & \text { Inflammatory bowel disease } \\ \text { iNKT } & \text { Invariant natural killer T (cell) } \\ \text { MAIT } & \text { Mucosal-associated invariant T (cell) } \\ \text { MR1 } & \text { MHC-Ib-related protein 1 } \\ \text { NK } & \text { Natural killer } \\ \text { PBMC } & \text { Peripheral blood mononuclear cell } \\ \text { PD-1 } & \text { Programmed cell death protein 1 } \\ \text { PMA } & \text { Phorbol myristic acid }\end{array}$

$\begin{array}{ll}\text { SLE } & \text { Systemic lupus erythematosus } \\ \text { TCR } & \text { T cell receptor } \\ \text { UCT cell } & \text { Unconventional T cell }\end{array}$

\section{Introduction}

Type 1 diabetes is a chronic autoimmune disease caused by progressive $\mathrm{T}$ cell-mediated destruction of insulin-producing beta cells in the pancreas [1]. The clinical presentation of type 1 diabetes is preceded by a period of asymptomatic autoimmunity, during which autoantibodies to islet antigens are almost invariably detected $[2,3]$. 
The incidence of type 1 diabetes has increased considerably in the past 30 years $[4,5]$. Despite over 50 susceptibility loci shown to contribute to the development of type 1 diabetes in humans [ 6 , 7], the autoimmune process in genetically at-risk individuals is probably driven by environmental factors, such as infections and diet [8]. Importantly, the composition of the intestinal microbiome has recently been associated with the development of type 1 diabetes. Compared with healthy control individuals of similar age, both patients with type 1 diabetes [9-12] and autoantibodypositive $\left(\mathrm{AAb}^{+}\right)$children at risk for type 1 diabetes [13-16] have been reported to display decreased bacterial diversity as well as intestinal dysbiosis commonly characterised by increased numbers of Bacteroidetes species in the gut microbiome.

The intestinal microbiome also plays a key role in the development of certain subsets of innate-like $\mathrm{T}$ cells, such as the mucosal-associated invariant $\mathrm{T}$ (MAIT) cells. MAIT cells are preferentially localised in mucosal tissues, including gut, and are largely absent in germ-free mice $[17,18]$. Together with $\gamma \delta \mathrm{T}$ cells and invariant natural killer T (iNKT) cells, MAIT cells are classified as unconventional T cells (UCTs) [19]. MAIT cells express a conserved $\mathrm{T}$ cell receptor (TCR) comprising an invariant $\mathrm{V} \alpha 7.2-\mathrm{J} \alpha 33$ chain, and they recognise metabolites originating from microbial biosynthesis presented by MHC-Ib-related protein 1 (MR1) on antigen-presenting cells [19]. Upon activation, MAIT cells produce several proinflammatory cytokines, such as IFN- $\gamma$ and IL-17A, and display cytotoxic effector function against cells infected with certain pathogens [20]. Similar to conventional T cells, MAIT cells develop in the thymus before migrating into the peripheral blood and accumulate in circulation with age $[18,21$, 22]. Human peripheral blood MAIT cells express high levels of CD 161 and IL-18 receptor $\alpha$, which together with TCR V $\alpha 7.2$ can be used in their identification [21].

In recent years, alterations in the circulating MAIT compartment have been observed in multiple autoimmune diseases, such as inflammatory bowel disease (IBD) [23-26], systemic lupus erythematosus (SLE) [27, 28], rheumatoid arthritis [27, 29, 30] and multiple sclerosis [31-33]. The first published study on MAIT cells in patients with type 1 diabetes reported a comparable frequency of circulating $\mathrm{CD} 8^{+} \mathrm{CD} 161^{\text {bright }}$ 'MAIT-like' cells in individuals with type 1 diabetes compared with healthy control individuals [34]. A more recent study observed a markedly reduced frequency of circulating MAIT cells in patients with newly diagnosed type 1 diabetes [35]. One more study suggested that the frequency of circulating MAIT cells was also reduced in $\mathrm{AAb}^{+}$at-risk individuals [36]. Variable alterations in CD25, programmed cell death protein 1 (PD-1), C-C chemokine receptor type (CCR)6 and CD27 surface marker expression, as well as IFN- $\gamma$ and IL-4 production, by peripheral blood MAIT cells from individuals with type 1 diabetes have also been reported in these studies [34, 35].

In order to better understand the role of MAIT cells during type 1 diabetes development, we analysed blood MAIT cell frequency, phenotype and function in samples from individuals at different stages of diabetes progression.

\section{Methods}

Study participants The paediatric study cohort comprised a total of 51 children with newly diagnosed type 1 diabetes, $27 \mathrm{AAb}^{+}$children, and 113 autoantibody-negative healthy children (Table 1). Among the $\mathrm{AAb}^{+}$children, 11 were diagnosed with type 1 diabetes 3-33 months (mean \pm SD $13.7 \pm$ 10.5 months) after sampling (progressors) and 16 had not progressed to clinical disease (non-progressors) during the mean 3 year follow-up after sampling. Except for children with newly diagnosed type 1 diabetes, all study participants, including the autoantibody-negative healthy control children, participated in the Finnish Type 1 Diabetes Prediction and Prevention (DIPP) follow-up study and had HLA genotypes associated with increased risk for type 1 diabetes [37]. Autoantibody-positivity was analysed in the children at sampling, as previously described [2]. $\mathrm{AAb}^{+}$children were positive for two or more biochemical autoantibodies (insulin autoantibodies [IAA], insulinoma-associated-2 antibodies [IA-2A], GAD antibodies [GADA] and/or zinc transporter 8 autoantibodies [ZnT8A]).

The adult study cohort comprised 33 adults with established type 1 diabetes and 37 healthy individuals (Table 1).

The study was approved by local ethics committees in the participating university hospitals. All individuals participating in the study and/or their legal guardians provided written informed consent, as mandated by the Declaration of Helsinki.

PBMC sample preparation Peripheral blood mononuclear cells (PBMCs) were isolated from peripheral blood samples as previously described [38]. Fresh PBMCs from paediatric participants and frozen PBMCs (cryopreserved in $10 \%$ DMSO) from adult participants were used for cell culture and immunostaining experiments.

Cell culture and stimulation PBMCs were seeded in U-bottom 96-well plates $\left(10^{6}\right.$ per $200 \mu \mathrm{l}$ per well) and cultured for 16 $18 \mathrm{~h}\left(37^{\circ} \mathrm{C}, 5 \% \mathrm{CO}_{2}\right)$ in RPMI 1640 complete medium with $5 \%$ human $\mathrm{AB}$ serum. Cells were either left unstimulated or stimulated with whole Escherichia coli bacteria (ATCC strain 25922, Manassas, VA, USA) fixed with $1 \%$ paraformaldehyde for $5 \mathrm{~min}$ [39], or with a combination of IL-12 and IL18 (both at $50 \mathrm{ng} / \mathrm{ml}$, Peprotech, Cranbury, NJ, USA). Some samples were preincubated either with anti-MR1 blocking antibody $(20 \mu \mathrm{g} / \mathrm{ml}$, clone 26.5, BioLegend, San Diego, CA, USA) or with IgG2a isotype control ( $20 \mu \mathrm{g} / \mathrm{ml}$, clone MPOC173, BioLegend) prior to E.coli stimulation. 
Table 1 Characteristics of study participants

\begin{tabular}{llllll}
\hline Participant group & $n$ (male/female) & $\begin{array}{l}\text { Age (years) } \\
(\text { mean } \pm \text { SD) }\end{array}$ & Range (years) & $\begin{array}{l}\text { T1D duration } \\
(\text { mean } \pm \text { SD) }\end{array}$ & Range \\
\hline Paediatric T1D & $51(25 / 26)$ & $8.6 \pm 3.9$ & $2-15$ & $<1$ week & N/A \\
Paediatric AAb ${ }^{+}$ & $27(14 / 13)$ & $8.6 \pm 4.5$ & $2-15$ & N/A & N/A \\
$\quad$ Progressors & $11(6 / 5)$ & $7.7 \pm 4.5$ & $2-13$ & N/A & N/A \\
$\quad$ Nonprogressors & $16(8 / 8)$ & $9.0 \pm 4.5$ & $2-15$ & N/A & N/A \\
Paediatric control & $113(64 / 49)$ & $8.9 \pm 3.9$ & $2-15$ & N/A & N/A \\
Adult T1D & $33(19 / 14)$ & $27.1 \pm 6.4$ & $19-39$ & $11.9 \pm 8.0 \mathrm{y}$ & $0.4-30 \mathrm{y}$ \\
Adult control & $37(14 / 23)$ & $26.2 \pm 4.4$ & $20-38$ & N/A & N/A \\
\hline
\end{tabular}

N/A, not applicable; T1D, type 1 diabetes; y, years
Flow-cytometric analyses Viability staining was performed on PBMCs using Zombie Aqua dye (BioLegend) according to the manufacturer's instructions. Immunostaining for surface markers was subsequently performed on at least $10^{6}$ PBMCs per staining by incubating the cells with a panel of fluorochrome-labelled antibodies (ESM Table 1) for 20-30 min. For cytokine analyses PBMCs were stimulated for $5 \mathrm{~h}$ with $20 \mathrm{ng} / \mathrm{ml}$ phorbol myristic acid (PMA; Sigma Aldrich, St Louis, MO, USA), $500 \mathrm{ng} / \mathrm{ml}$ ionomycin (Sigma Aldrich), and $3 \mu \mathrm{g} / \mathrm{ml}$ brefeldin A (eBioscience, San Diego, CA, USA). Fixation and permeabilisation were performed using the Intracellular Fixation and Permeabilization Buffer set (eBioscience), followed by staining for intracellular cytokines (ESM Table 1) for $30 \mathrm{~min}$. The samples were acquired on FACSCanto II (BD Biosciences, San Jose, CA, USA) or Cytoflex S (Beckman Coulter, Indianapolis, IN, USA) flow cytometers (ESM Table 1). Coded samples were used throughout, and flowcytometric data was analysed by FlowJo v10.4.2 (BD) blinded to the clinical classification of the sample.

Statistical analyses Statistical analyses were performed using Prism software version 7.05 (GraphPad Software, San Diego, CA, USA). Mann-Whitney $U$ test or Kruskal-Wallis test with Dunn's multiple comparison post hoc test were used for statistical comparisons. No power calculations were made as the study was exploratory in nature with very limited previous data to support the calculations, and sample sizes were determined in part by feasibility. Age as a covariate was addressed by comparing the slopes and/or elevations of linear regression lines. Relationships between different variables were examined using Spearman correlation coefficient. To increase statistical power, samples from different study groups were pooled for correlation analyses in cases where the slopes of the linear regression lines did not differ statistically between the study groups. A $p$ value $<0.05$ was considered to indicate statistical significance.

\section{Results}

Decreased frequency of MAIT cells in AAb ${ }^{+}$children who later progressed to type 1 diabetes and in adult patients a short time after onset of diabetes We first analysed the frequency of circulating $\mathrm{CD} 3^{+} \mathrm{V} \alpha 7.2^{+} \mathrm{CD} 161^{+}$MAIT cells (Fig. 1a and ESM Fig. 1) in paediatric and adult cross-sectional cohorts (Table 1). In the paediatric cohort, the frequency of MAIT cells within the $\mathrm{CD}^{+} \alpha \beta^{+} \mathrm{T}$ cell compartment was similar across the study groups (Fig. 1b). In accordance with previous reports [18, 21, 22], the frequency of MAIT cells demonstrated considerable interindividual variation and a strong positive correlation with the age of children $(r=0.59, p<0.0001)$, with almost a tenfold increase in mean frequency between the ages of 2 and 15 years (Fig. 1c). However, even after stratification by age, we observed no differences in total MAIT cell frequencies between the study groups (Fig. 1c). Moreover, sex, HLA class II genotype, and blood glucose and $\mathrm{HbA}_{1 \mathrm{c}}$ levels did not appear to affect MAIT cell frequencies in the paediatric cohort (ESM Fig. 2). Although the frequency of MAIT cells was overall unaltered in $\mathrm{AAb}^{+}$atrisk children (Fig. 1b), we interestingly observed that those $\mathrm{AAb}^{+}$children who later progressed to type 1 diabetes had a decreased frequency of MAIT cells compared with control individuals (median $0.44 \%$ vs $0.96 \%$ of $\mathrm{CD}^{+} \mathrm{T}$ cells, $p=$ 0.04 ; Fig. 1d). This result remained significant even after stratifying for age (Fig. 1e).

In the adult cohort, no differences in the frequency of MAIT cells were observed between adult patients with type 1 diabetes and healthy control individuals (Fig. 1f). Moreover, the frequency of MAIT cells in adults did not demonstrate correlation with age, sex, $\mathrm{BMI}$ or $\mathrm{HbA}_{1 \mathrm{c}}$ levels, or the duration of disease (ESM Fig. 2). However, we noted that some adult patients with a short disease duration had extremely low MAIT cell frequencies for adult individuals $\left(<0.6 \%\right.$ of $\mathrm{CD}^{+}$ T cells; ESM Fig. 2). Consequently, when adult patients with diabetes were arbitrarily divided into two groups based on disease duration $[<6$ (mean 2.6) and $>6$ (mean 15.5) years after diagnosis], five of the ten patients with $<6$ years after 

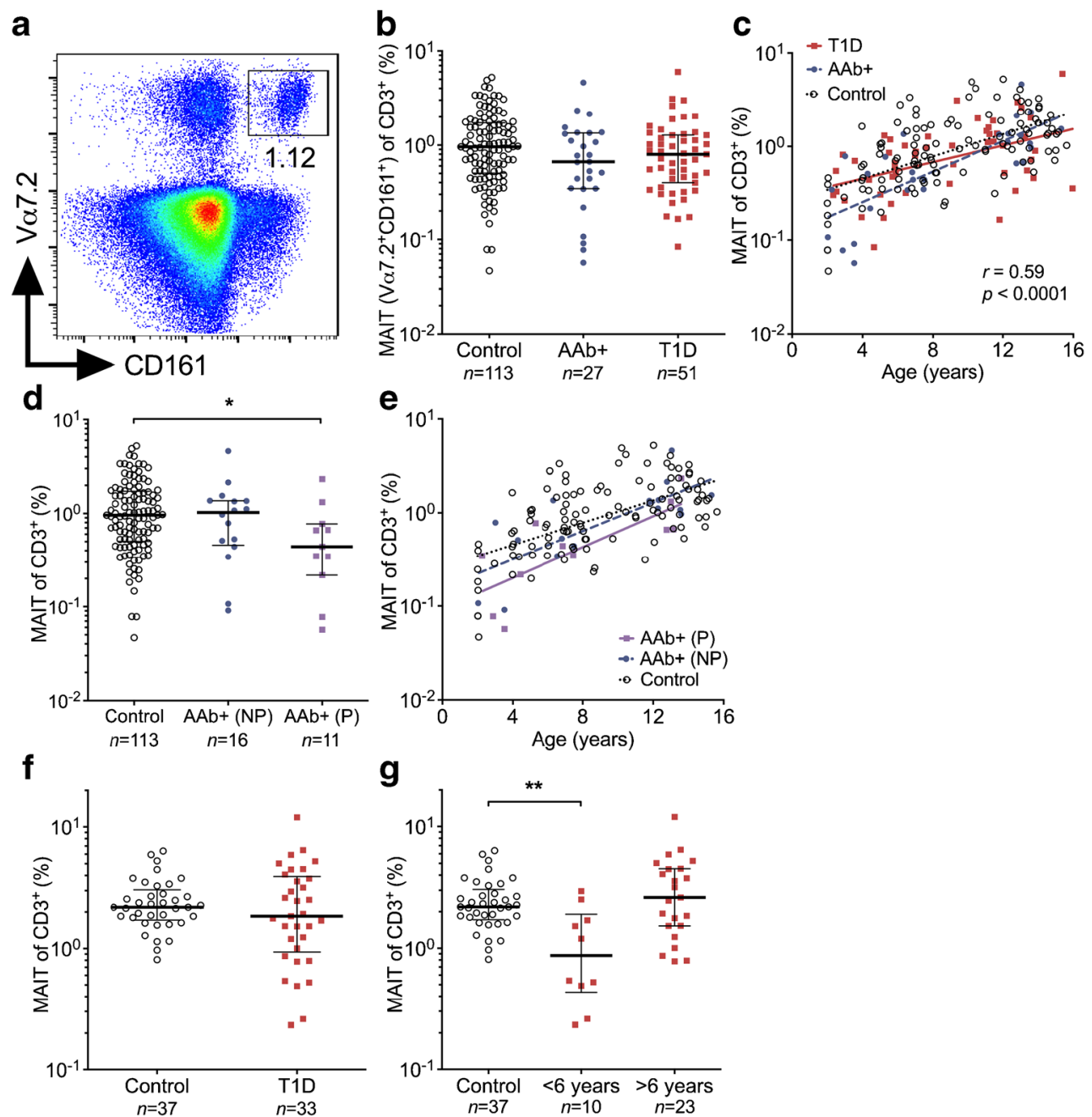

Fig. 1 Decreased frequency of circulating MAIT cells in $\mathrm{AAb}^{+}$children who progressed to type 1 diabetes (T1D) and in adult patients with a short duration of T1D. Representative example of flow cytometry gating of $\mathrm{CD}^{+} \mathrm{V} \alpha 7.2^{+} \mathrm{CD} 161^{+}$MAIT cells (a). The frequency of circulating MAIT cells in control, $\mathrm{AAb}^{+}$and T1D groups in the paediatric cohort (b). Linear regression lines for $\log _{10}$-transformed MAIT cell frequencies vs age were calculated for the control, $\mathrm{AAb}^{+}$and T1D groups (c). The slopes and elevations of the regression lines were not statistically different between the groups. Correlation with age was calculated by pooling all samples analysed and is expressed together with the $p$ value on the plot.

MAIT cell frequency in $\mathrm{AAb}^{+}$children who did not progress (NP) or progressed $(\mathrm{P})$ to T1D during the follow-up (d). Linear regression lines for $\log _{10^{-}}$transformed MAIT cell frequencies vs age were calculated for the control, $\mathrm{AAb}^{+}$non-progressor and $\mathrm{AAb}^{+}$progressor groups $(\mathbf{e})$. The elevations of the regression lines were statistically different among the groups $(p<0.05)$. Frequency of MAIT cells in adult healthy control individuals and adult patients with T1D (f) and in adult T1D patients with $<6$ years or $>6$ years since T1D diagnosis $(\mathbf{g})$. $(\mathbf{b}, \mathbf{d}, \mathbf{f}, \mathbf{g})$ Median values with IQRs are shown, plotted on a $\log _{10}$ scale. $* p<0.05$, $* * p<0.01$; Kruskal-Wallis test with Dunn's post hoc test

diagnosis had a markedly lower frequency of MAIT cells compared with the 23 patients with $>6$ years after diagnosis or the 37 healthy control individuals (Fig. 1g). The median frequency of MAIT cells in patients with $<6$ years after diagnosis was $0.87 \%$ compared with $2.19 \%$ in healthy control individuals $(p=0.007$; Fig. $1 \mathrm{~g})$.

In conclusion, no drastic changes in peripheral blood MAIT cell frequencies were observed in individuals with type 1 diabetes-associated autoimmunity. However, in subgroup analyses $\mathrm{AAb}^{+}$at-risk children who later progressed to clinical diabetes as well as adult patients a short time after diagnosis displayed lower frequencies of circulating MAIT cells.
Increased proportion of $\mathrm{CD}^{-} \mathrm{CD} 27^{-}$MAIT cells in children with newly diagnosed type 1 diabetes We next analysed the frequencies of MAIT cell subsets expressing CD8 and/or CD27 (Fig. 2a). In the paediatric cohort, the proportion of $\mathrm{CD} 8{ }^{+} \mathrm{CD} 27^{+}$MAIT cells was decreased and that of $\mathrm{CD} 8^{-} \mathrm{CD} 27^{-}$MAIT cells increased in children with type 1 diabetes compared with control children (median $63.9 \%$ vs $67.1 \%$ of MAIT cells, $p=0.04$, and median $4.6 \%$ vs $3.1 \%$ of MAIT cells, $p=0.004$, respectively; Fig. $2 \mathrm{~b}$, c), while the $\mathrm{CD} 8^{+} \mathrm{CD} 27^{-}$and $\mathrm{CD} 8^{-} \mathrm{CD} 27^{+}$MAIT cell subsets remained unaltered (ESM Fig. 3). These results remained significant even after stratifying for age (Fig. 2d, e). Importantly, no 
Fig. 2 Proportional increase of $\mathrm{CD} 8^{-} \mathrm{CD} 27^{-}$MAIT cells in children with newly diagnosed type 1 diabetes (T1D).

Representative example of flow cytometry gating of CD8 and CD27 expression on MAIT cells (a). Proportions of $\mathrm{CD} 8^{+} \mathrm{CD} 27^{+}$ (b) and $\mathrm{CD} 8^{-} \mathrm{CD} 27^{-}$(c) MAIT cells in control, $\mathrm{AAb}^{+}$and $\mathrm{T} 1 \mathrm{D}$ groups. Linear regression lines for $\mathrm{CD} 8^{+} \mathrm{CD} 27^{+}(\mathbf{d})$ and

$\mathrm{CD} 8^{-} \mathrm{CD} 27^{-}$(e) MAIT cell frequencies vs age were calculated for the control, $\mathrm{AAb}^{+}$ and T1D groups. The elevations of the regression lines were significantly different among the groups $(p<0.05)$. Correlation with age was calculated by pooling all samples analysed and is expressed together with $p$ values on the individual plots. Proportions of PD- $1^{+}(\mathbf{f})$ and $\mathrm{CD}^{2} 5^{+}(\mathrm{g}) \mathrm{MAIT}$ cells in control, $\mathrm{AAb}^{+}$and T1D groups. (b, c, f, $\mathbf{g}$ ) Median values with IQRs are shown. *p<0.05, **p $<0.01$; Kruskal-Wallis test with Dunn's post hoc test a

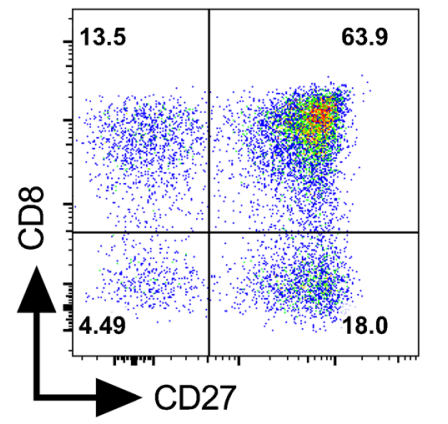

d

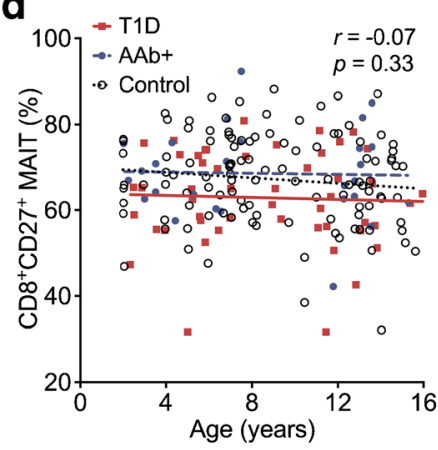

f

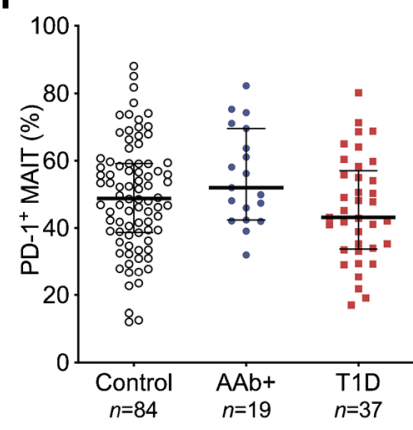

b

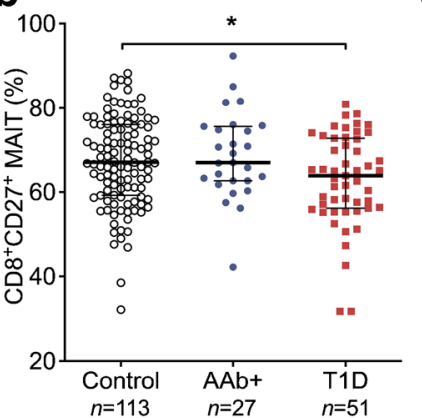

e

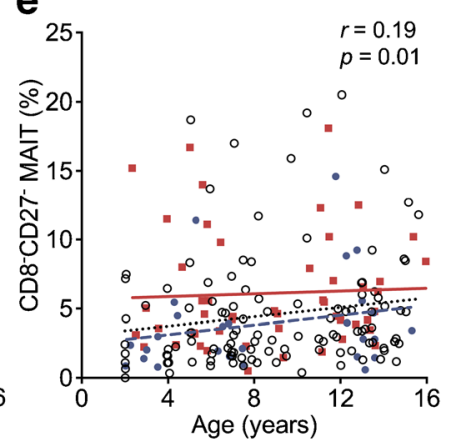

g

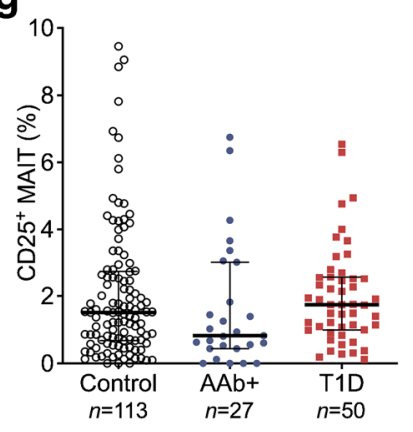

C

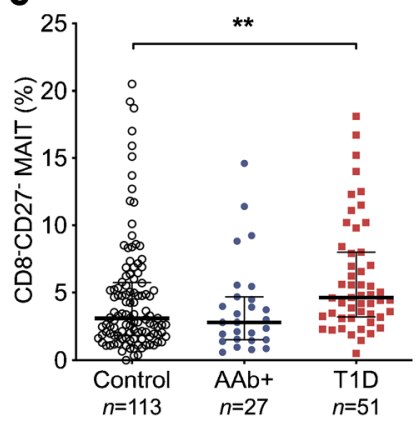

differences in conventional $\mathrm{CD} 3^{+} \mathrm{V} \alpha 7.2^{+} \mathrm{CD} 161^{-}$(nonMAIT), $\mathrm{CD} 8^{+} \mathrm{CD} 27^{+}$or $\mathrm{CD} 8^{-} \mathrm{CD} 27^{-} \mathrm{T}$ cell frequencies were observed between the groups (ESM Fig. 3), demonstrating that the observed alterations are specific to MAIT cells. No differences in the frequencies of $\mathrm{CD} 8^{+} \mathrm{CD} 27^{+}$or $\mathrm{CD} 8^{-} \mathrm{CD} 27^{-}$ MAIT cells were observed in $\mathrm{AAb}^{+}$children, even after stratification for progressors and nonprogressors, or in adult patients with type 1 diabetes (Fig. 2b, c and ESM Figs 3 and 4). There were also no differences in MAIT cells expressing the activation markers PD-1 and CD25 between the study groups in either the paediatric or adult cohorts (Fig. 2f, $g$ and ESM Figs 3 and 4). In conclusion, we observed an increased proportion of $\mathrm{CD} 8^{-} \mathrm{CD} 27^{-}$MAIT cells in children with newly diagnosed type 1 diabetes.

\section{Decreased CCR5, $\beta 7$ integrin and IFN- $\gamma$ expression on MAIT} cells in children with newly diagnosed type 1 diabetes To better characterise the phenotype of MAIT cells during the progression to type 1 diabetes, we analysed the expression of homing receptors and cytokine production by MAIT cells

in the paediatric cohort (ESM Fig. 1). MAIT cells express higher levels of CCR5 and CCR6 but similar levels of $\beta 7$ integrin compared with non-MAIT T cells (Fig. 3a-c). We observed decreased levels of CCR5 and $\beta 7$ integrin but not CCR6 expression on MAIT cells in children with type 1 diabetes compared with control children (median $90.0 \%$ vs $94.3 \% \mathrm{CCR}^{+}$MAIT cells, $p=0.02$, and median $73.5 \%$ vs $81.7 \%$ of $\beta 7$ integrin $^{+}$ MAIT cells, $p=0.004$, respectively; Fig. $3 \mathrm{~d}-\mathrm{f}$ ), even after stratification by age (ESM Fig. 5). The decrease in CCR5 expression appeared to be specific to MAIT cells since it was not altered in non-MAIT T cells (ESM Fig. 5). In contrast, $\beta 7$ integrin expression was also decreased in non-MAIT T cells (as well as total $\mathrm{CD}^{+} \mathrm{T}$ cells) in children with type 1 diabetes compared with control children (median $66.8 \%$ vs $77.5 \%$ of non-MAIT T cells, $p<0.0001$ ), suggesting a more global alteration of $\beta 7$ integrin expression on $\mathrm{T}$ cells in children with type 1 diabetes (Fig. $3 \mathrm{~g}$ and ESM Fig. 5). No changes in CCR5, CCR6 or $\beta 7$ integrin expression were observed in $\mathrm{AAb}^{+}$children (Fig. $3 \mathrm{~d}-\mathrm{f}$ and $\mathrm{ESM}$ Fig. 4). 
Fig. 3 Lower expression of CCR 5, $\beta 7$ integrin and IFN- $\gamma$ on MAIT cells from children with newly diagnosed type 1 diabetes (T1D). Representative examples of CCR5 (a), CCR6 (b) and $\beta 7$ integrin (c) staining in

fluorescence minus one (FMO) control (dotted lines), non-MAIT $\mathrm{T}$ cells (dashed lines) and MAIT cells (solid lines). Frequencies of $\mathrm{CCR}^{+}(\mathbf{d}), \mathrm{CCR}^{+}(\mathbf{e})$ and $\beta 7$ integrin $^{+}$(f) MAIT cells as well as $\beta 7$ integrin $^{+}$non-MAIT T cells (g) in control, $\mathrm{AAb}^{+}$and $\mathrm{T} 1 \mathrm{D}$ groups. Representative examples of IFN- $\gamma$, IL-17A and IL-4 production by MAIT cells (h, i). Frequencies of IFN- $\gamma^{+}(\mathbf{j})$, IL$17 \mathrm{~A}^{+}(\mathbf{k})$ and IL- $4^{+}(\mathbf{l})$ MAIT cells in control, $\mathrm{AAb}^{+}$and T1D groups. $(\mathbf{d}-\mathbf{g}, \mathbf{j}-\mathbf{l})$ Median values with IQRs are shown. $* p<0.05, * * p<$ 0.01 , *** $p<0.001$; Kruskal-

Wallis test with Dunn's post hoc test a
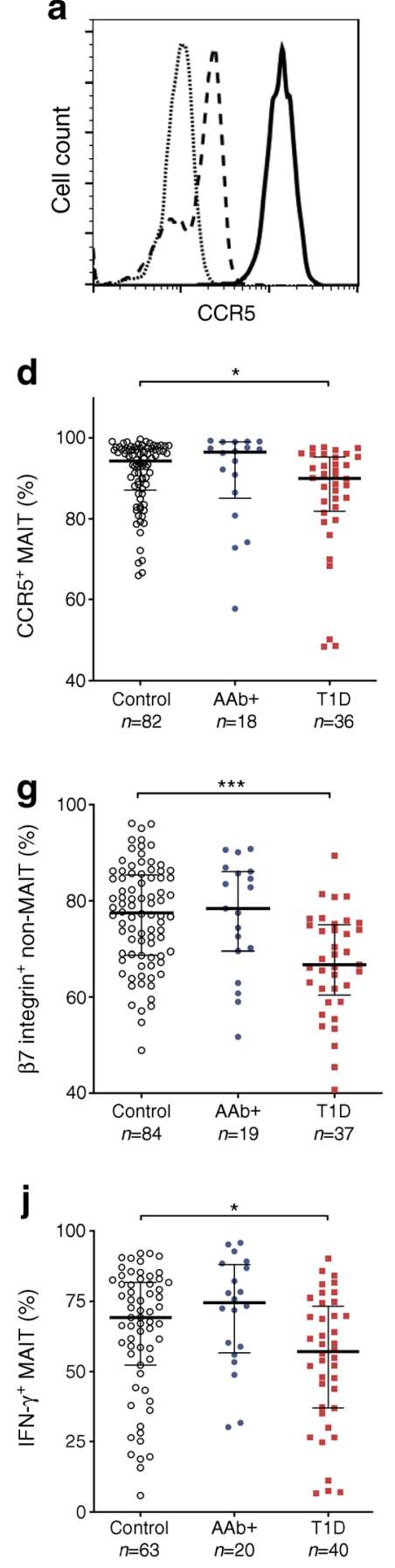

k

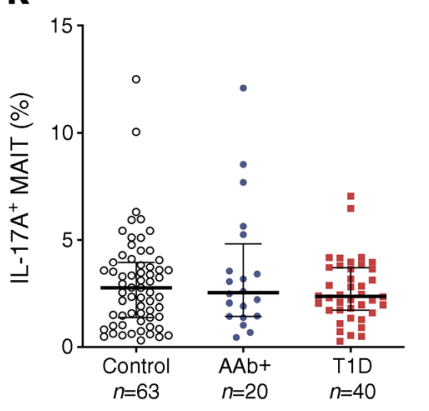

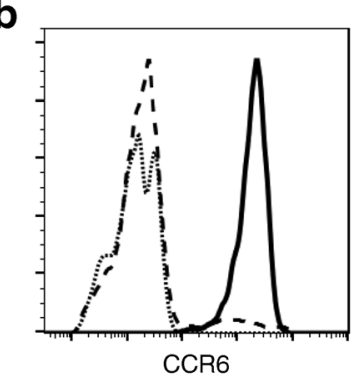

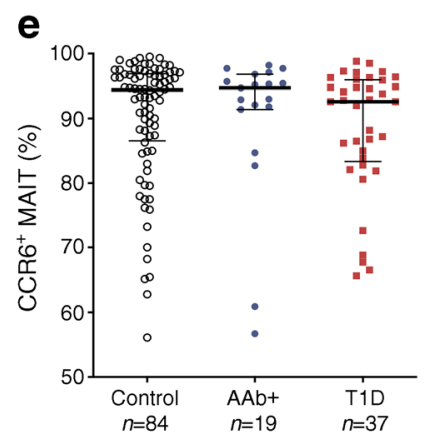

h

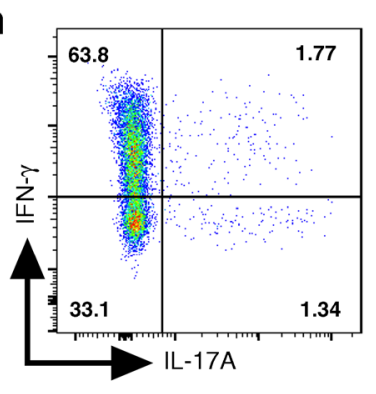

C
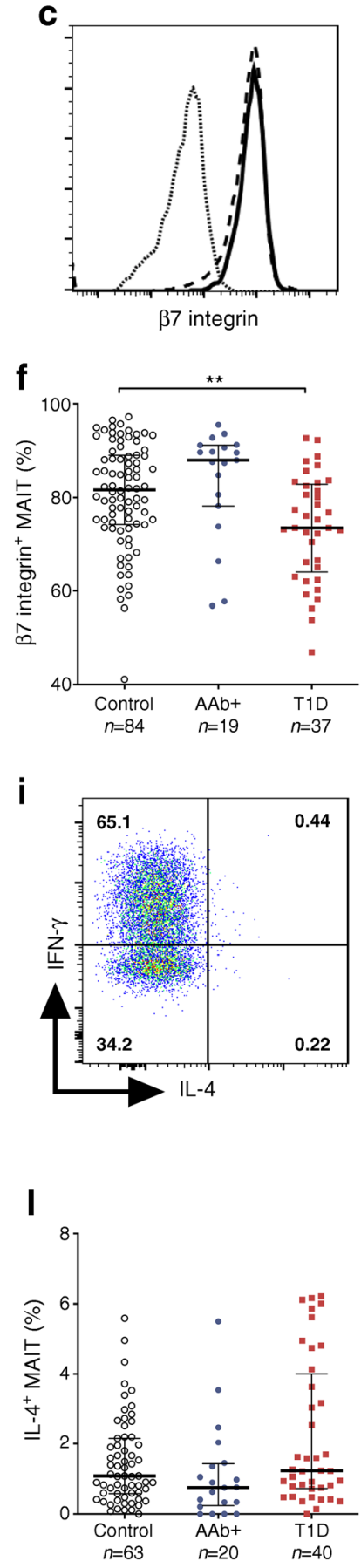

To investigate the cytokine production profile of circulating MAIT cells, we stimulated PBMCs with PMA and ionomycin and analysed the production of IFN- $\gamma$, IL-17A and IL-4 (Fig. $3 \mathrm{~h}, \mathrm{i})$. The frequency of IFN- $\gamma^{+}$MAIT cells was reduced in children with type 1 diabetes compared with control children (median $57.1 \%$ vs $69.3 \%$ of MAIT cells, $p=0.04$; Fig. $3 \mathrm{j}$ ). However, no differences in the frequencies of IL-17A $\mathrm{A}^{+}$IL- $4^{+}$, IFN- $\gamma^{+} \mathrm{IL}-17 \mathrm{~A}^{+}$or IFN $-\gamma^{+} \mathrm{IL}-4^{+}$MAIT cells were observed (Fig. 3k, 1 and ESM Fig. 5). The frequency of IFN- $\gamma^{+}$nonMAIT T cells was not altered (ESM Fig. 5). Once again, no differences in cytokine production were observed in $\mathrm{AAb}^{+}$children (Fig. 3j-1 and ESM Fig. 4). In conclusion, we observed that the expression of CCR5 and $\beta 7$ integrin and the production of IFN- $\gamma$ by MAIT cells were lower in children with newly diagnosed type 1 diabetes.

Lower expression of $\beta 7$ integrin and lower production of IFN- $\gamma$ by $\mathrm{CD}^{-} \mathrm{CD}^{-} 7^{-}$MAIT cells We next analysed whether the observed decrease in CCR5, $\beta 7$ integrin and IFN- $\gamma$ expression was mechanistically linked to the proportional 
Fig. 4 CCR5, $\beta 7$ integrin and IFN- $\gamma$ expression on CD8 ${ }^{-} \mathrm{CD} 27^{-}$MAIT cells. Linear regression lines for $\mathrm{CCR}^{+}(\mathbf{a})$, $\beta 7$ integrin $^{+}(\mathbf{b})$ and IFN- $\gamma^{+}(\mathbf{c})$ MAIT cell frequencies vs $\mathrm{CD} 8^{-} \mathrm{CD} 27^{-}$MAIT cell frequencies were calculated for the control, $\mathrm{AAb}^{+}$and type 1 diabetes (T1D) groups. The slopes of the regression lines were not significantly different between the groups. Correlation with $\mathrm{CD} 8{ }^{-} \mathrm{CD} 27^{-}$MAIT cell frequencies was calculated by pooling all samples analysed and is expressed together with $p$ values on the individual plots. Representative example of CD8 and CD4 expression on peripheral blood MAIT cells (d). The frequencies of MAIT cells that belong to the $\mathrm{CD} 8^{+}, \mathrm{DN}, \mathrm{CD} 4^{+}$ and DP subsets (e), and that belong to the $\mathrm{CD} 8^{+} \mathrm{CD} 27^{+}$, $\mathrm{CD} 8^{+} \mathrm{CD} 27^{-}, \mathrm{DN} \mathrm{CD} 27^{+}$and $\mathrm{DN}$ $\mathrm{CD} 27^{-}$subsets $(\mathbf{f})$. Frequencies of $\mathrm{CCR}^{+}(\mathbf{g}), \beta 7$ integrin $^{+}(\mathbf{h})$ and IFN $-\gamma^{+}$(i) cells within the MAIT cell subsets. The data in (e-i) represent a combined analysis of a total of 17 different healthy children. (e-i) Median values with IQRs are shown. $* p<0.05$, $* * p<0.01, * * * p<0.001$;

Kruskal-Wallis test with Dunn's post hoc test

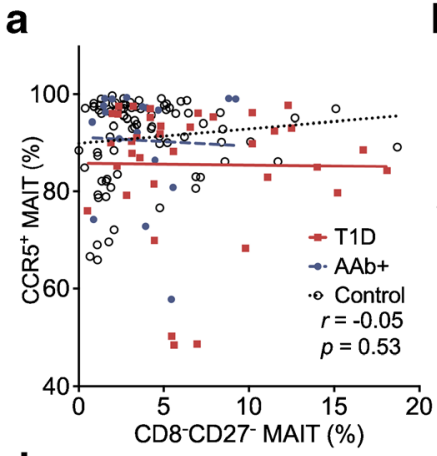

d
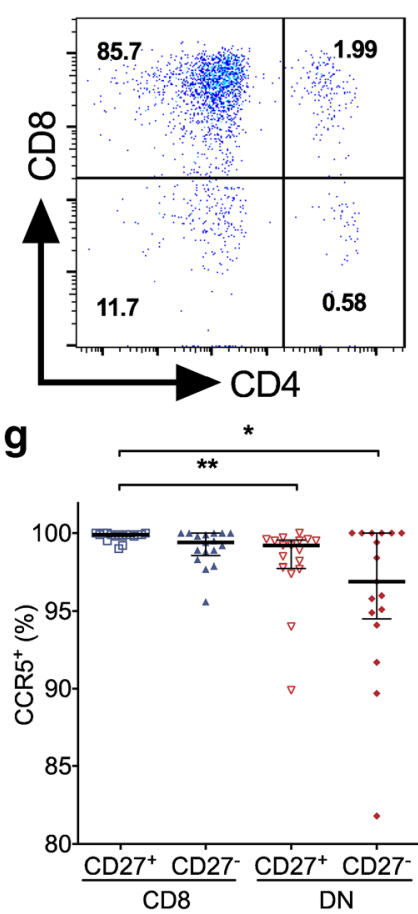

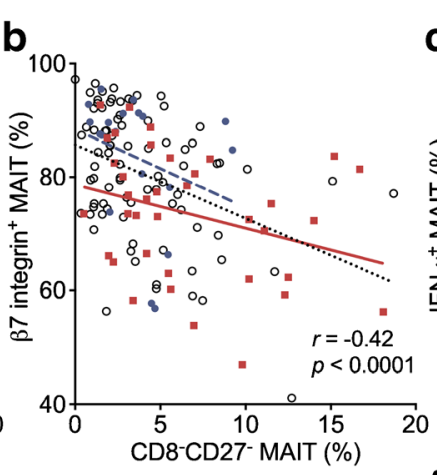

e

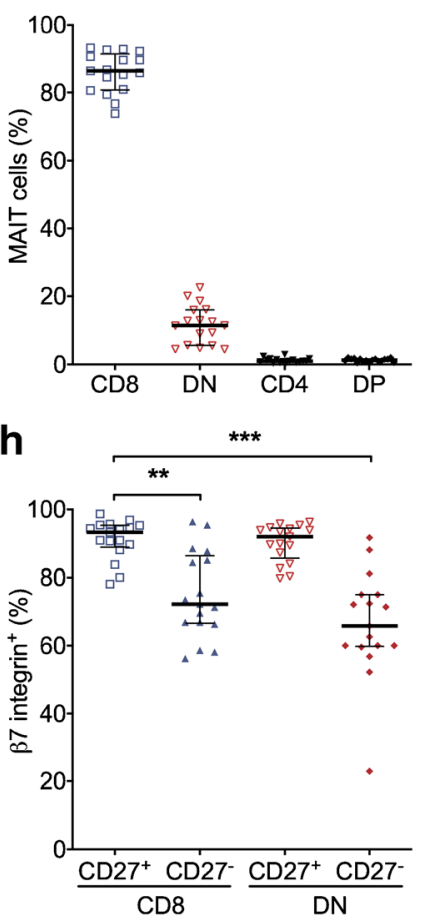

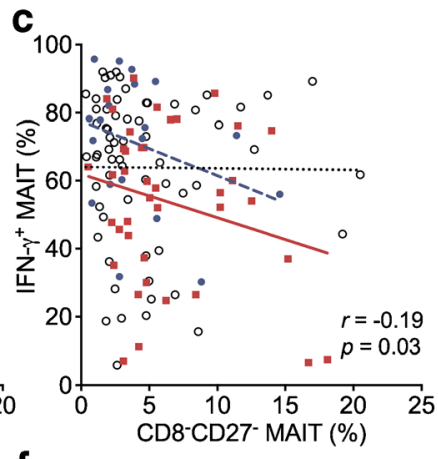

f

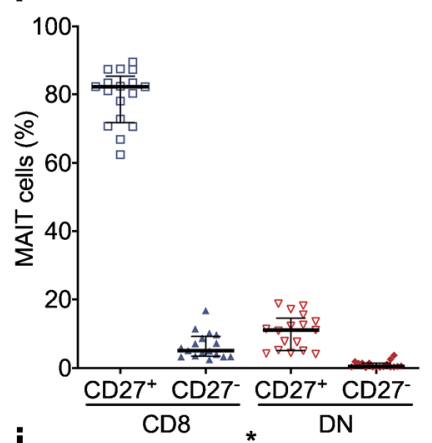

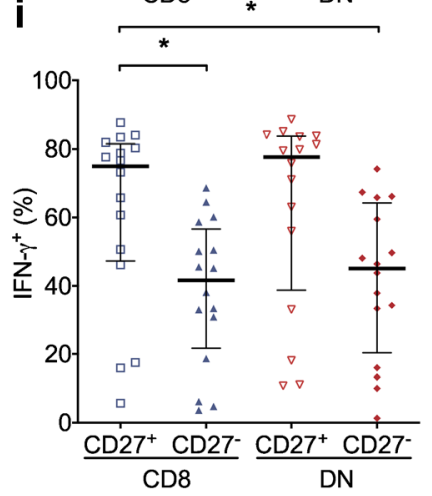

increase in $\mathrm{CD}^{-} \mathrm{CD} 27^{-}$MAIT cells in children with type 1 diabetes. The frequencies of $\beta 7$ integrin $^{+}$and IFN $-\gamma^{+}$MAIT cells inversely correlated with the frequencies of $\mathrm{CD} 8^{-} \mathrm{CD} 27^{-}$MAIT cells in the paediatric cohort, while the frequencies of $\mathrm{CCR} 5^{+}$MAIT cells did not demonstrate such correlation (Fig. 4a-c).

To study this further, we analysed additional paediatric healthy donors with a broader flow cytometry panel incorporating all the markers in the same analysis. In line with previous studies [21, 40, 41], we observed that around $80-90 \%$ of MAIT cells are $\mathrm{CD} 8^{+}$and almost all the remaining cells are double negative (DN), while $\mathrm{CD}^{+}$and double positive (DP) MAIT cells are extremely rare (Fig. $4 \mathrm{~d}$, e). Therefore, the $\mathrm{CD} 8^{-} \mathrm{CD} 27^{-}$MAIT cells analysed so far are most likely to represent $\mathrm{DN} \mathrm{CD} 27^{-}$cells. $\mathrm{CD} 8^{+} \mathrm{CD} 27^{+}$MAIT cells represent about $80 \%$ of circulating MAIT cells followed by minor populations of $\mathrm{DN} \mathrm{CD} 27^{+}, \mathrm{CD} 8^{+} \mathrm{CD} 27^{-}$and $\mathrm{DN} \mathrm{CD} 27^{-}$MAIT cells (Fig. 4f). Next, we examined whether the expression of homing receptors and/or cytokines differs between the CD27-

positive or -negative $\mathrm{CD} 8^{+}$and $\mathrm{DN}$ subsets. The expression of CCR5 was lower on DN CD27 $7^{-}$and DN CD27 $7^{+}$compared with $\mathrm{CD} 8^{+} \mathrm{CD} 27^{+}$MAIT cells (Fig. 4g). Moreover, the frequencies of $\beta 7$ integrin $^{+}$and IFN- $\gamma^{+}$MAIT cells were lower in $\mathrm{CD} 8^{+} \mathrm{CD} 27^{-}$and DN CD27 $7^{-}$MAIT subsets compared with $\mathrm{CD} 8^{+} \mathrm{CD} 27^{+}$MAIT cells (Fig. 4h, i). Of note, the frequencies of IL- $4^{+}$MAIT cells were also lower but those of IL-17A ${ }^{+}$MAIT cells higher in $\mathrm{CD} 8^{+} \mathrm{CD} 27^{-}$and DN $\mathrm{CD} 27^{-}$MAIT subsets compared with $\mathrm{CD} 8^{+} \mathrm{CD} 27^{+}$MAIT cells (ESM Fig. 5).

Collectively, these analyses infer that the observed increase in CD8 ${ }^{-}$CD27 MAIT cells in children with type 1 diabetes (Fig. 2c) probably results from a proportional shift towards an increased frequency of DN CD27 MAIT cells. This, in turn, explains the decreased $\beta 7$ integrin expression and IFN- $\gamma$ production by MAIT cells from children with type 1 diabetes (Fig. 3), as they demonstrate an inverse correlation with the frequency of $\mathrm{CD}^{-} \mathrm{CD} 27$ MAIT cells and their expression is markedly lower on DN CD27 MAIT cells compared with $\mathrm{CD} 8^{+} \mathrm{CD} 27^{+}$MAIT cells. 
Fig. 5 Comparable frequencies of $\mathrm{CD} 25^{+} \mathrm{CD} 69^{+}$MAIT cells after stimulation in vitro with E.coli or the combination of IL-12 and IL18 in children with type 1 diabetes (T1D), $\mathrm{AAb}^{+}$children and control children. Representative example of $\mathrm{CD} 25^{+} \mathrm{CD} 69^{+}$MAIT cells in an unstimulated PBMC sample (a, left), and samples stimulated at a PBMC to E.coli ratio 1:10 (a, middle) or with IL-12+IL-18 (a, right). Frequencies of $\mathrm{CD} 25^{+} \mathrm{CD} 69^{+}$MAIT cells in samples stimulated at a PBMC to E.coli ratio 1:1 (b) and 1:10 (c), or with IL-12 and IL-18 (d) from paediatric control, $\mathrm{AAb}^{+}$and $\mathrm{T} 1 \mathrm{D}$ individuals. (b-d) Median values with IQRs are shown
Fig. 6 Increased frequency of IL17A-producing $\gamma \delta \mathrm{T}$ cells in children with newly diagnosed type 1 diabetes (T1D).

Frequencies of $\gamma \delta \mathrm{T}$ cells (a), iNKT cells (b) and NK cells (c) in control, $\mathrm{AAb}^{+}$and T1D groups. Linear regression lines for $\log _{10^{-}}$ transformed $\gamma \delta \mathrm{T}$ cell $(\mathbf{d})$, iNKT cell (e) and NK cell (f)

frequencies vs $\log _{10}$-transformed MAIT cell frequencies were calculated for the control, $\mathrm{AAb}^{+}$ and T1D groups. The slopes and elevations of the regression lines were not statistically different between the groups. Correlation was calculated by pooling all samples analysed and is expressed together with $p$ values on the individual plots.

Frequencies of IL-17A-producing $\gamma \delta \mathrm{T}$ cells $(\mathbf{g})$ and iNKT cells $(\mathbf{h})$ in control, $\mathrm{AAb}^{+}$and T1D groups. Median values with IQRs are shown; plotted on a $\log _{10}$ scale in (b). ${ }^{* *} p<0.01$; Kruskal-Wallis test with Dunn's post hoc test
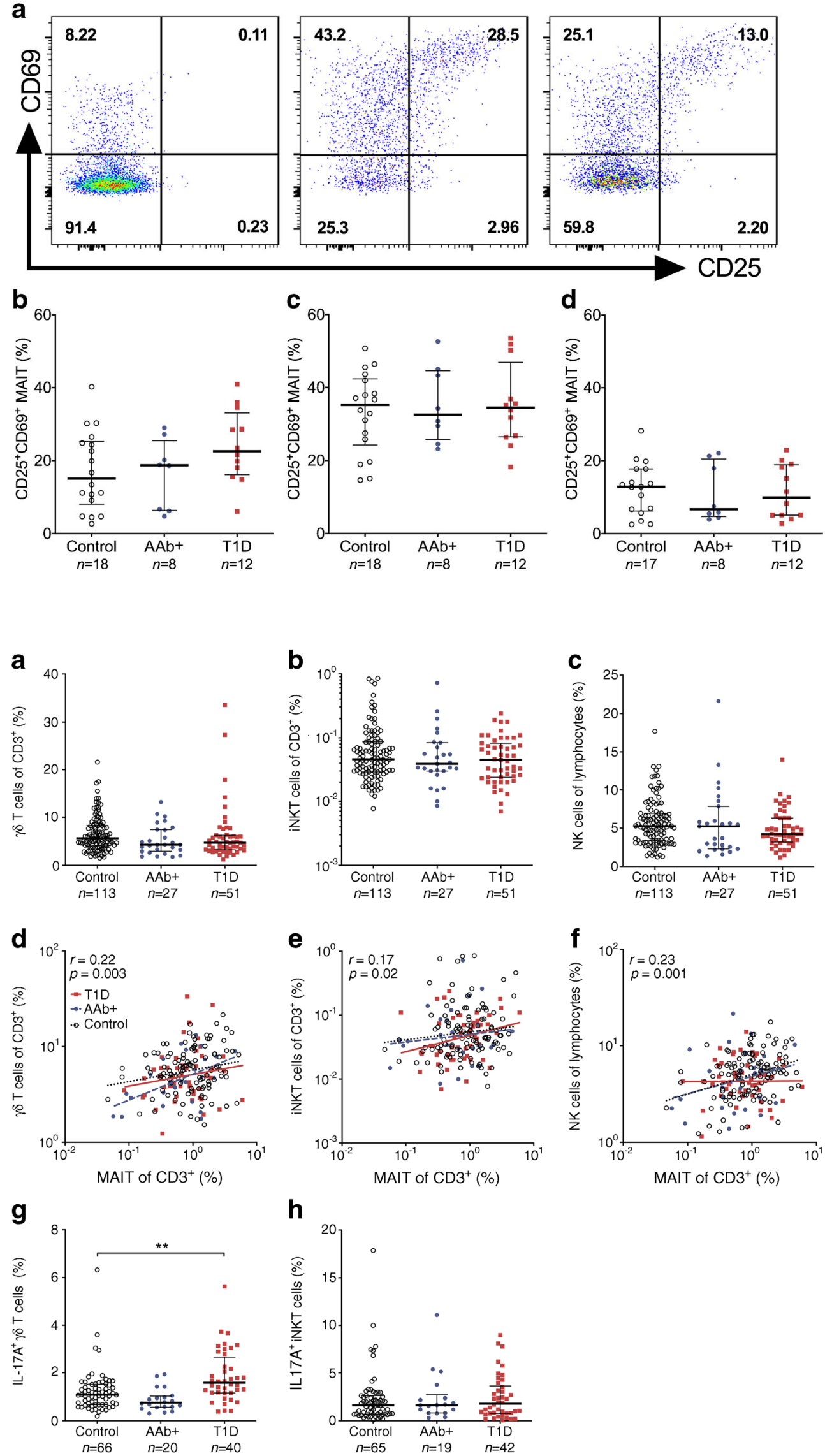
MR1-dependent and cytokine-driven functional responses are not altered in MAIT cells from children with newly diagnosed type 1 diabetes or from $\mathrm{AAb}^{+}$at-risk children To further investigate MAIT cell functionality during the progression of type 1 diabetes, PBMCs from 12 children with type 1 diabetes, nine $\mathrm{AAb}^{+}$children and 18 control children were stimulated either with whole E.coli bacteria (MR1-dependent activation [39]) or with the combination of IL-12 and IL-18 (MR1-independent activation [42]). Activation of MAIT cells (CD69 and CD25 upregulation) was subsequently analysed (Fig. 5a). No differences in the frequencies of $\mathrm{CD} 25^{+} \mathrm{CD} 69^{+}$MAIT cells were observed between the study groups upon stimulation with E.coli at two different concentrations (Fig. 5b, c) or with IL-12 and IL18 (Fig. 5d). Moreover, no differences in the frequencies of $\mathrm{CD} 25^{+} \mathrm{CD} 9^{+}$non-MAIT $\mathrm{T}$ cells were observed between the study groups (ESM Fig. 6). When anti-MR1 blocking antibodies were added to the E.coli stimulation, the frequencies of $\mathrm{CD} 25^{+} \mathrm{CD} 9^{+}$MAIT cells but not non-MAIT cells were markedly reduced (ESM Fig. 6), confirming that E.coli activates MAIT cells through MR1 presentation. In conclusion, no impairment of MAIT cell activation was observed in children with type 1 diabetes or $\mathrm{AAb}^{+}$at-risk children.

Increased frequency of IL-17A-producing $\gamma \delta$ T cells in children with newly diagnosed type 1 diabetes Finally, we analysed other peripheral blood UCT subsets, namely $\gamma \delta$ T cells and iNKT cells, as well as natural killer (NK) cells in our paediatric cohort (ESM Figs 1 and 7). The frequencies of these cell types were similar between the study groups (Fig. 6a-c and ESM Fig. 4). Interestingly, the frequencies of $\gamma \delta \mathrm{T}$ cells, iNKT cells and NK cells appeared to correlate with circulating MAIT frequencies (Fig. 6d-f). However, in contrast to MAIT cells, the frequencies of $\gamma \delta \mathrm{T}$ cells or iNKT cells did not increase with age and NK cells displayed only a modest positive correlation with age (ESM Fig. 8).

To investigate whether there are phenotypic alterations in $\gamma \delta \mathrm{T}$ cells and iNKT cells, we analysed the production of
IFN- $\gamma$, IL-17A and IL-4. No differences in the frequencies of IFN- $\gamma^{+}$and IL- $4^{+} \gamma \delta$ T cells and iNKT cells were observed between the study groups (ESM Fig. 8). However, IL-17A ${ }^{+}$ $\gamma \delta \mathrm{T}$ cells but not iNKT cells were more abundant in children with newly diagnosed type 1 diabetes compared with control children (median $1.58 \%$ vs $1.09 \%$ of $\gamma \delta \mathrm{T}$ cells, $p=0.002$; Fig. $6 \mathrm{~g}$ and $\mathrm{h}$ and ESM Fig. 8). In conclusion, no changes in $\gamma \delta \mathrm{T}$ cells, iNKT cells and NK cells were observed in children with newly diagnosed type 1 diabetes, with the exception of an increased production of IL-17A by $\gamma \delta \mathrm{T}$ cells.

\section{Discussion}

We observed multiple subtle alterations in the peripheral MAIT cell compartment through the analysis of crosssectional cohorts of individuals at different stages of type 1 diabetes progression (Fig. 7). In children with newly diagnosed type 1 diabetes, the proportion of $\mathrm{CD}^{-} \mathrm{CD} 27^{-}$(DN) MAIT cells was increased and the expression of the homing receptors CCR5 and $\beta 7$ integrin, as well as the production of IFN- $\gamma$ by MAIT cells was decreased. Moreover, the frequency of MAIT cells was decreased in $\mathrm{AAb}^{+}$at-risk children who later progressed to type 1 diabetes and in adult patients with a short duration of type 1 diabetes. No alterations in MAIT cells were observed in $\mathrm{AAb}^{+}$at-risk children who did not progress to diabetes during our follow-up or in adult type 1 diabetes patients with a long disease duration. These alterations were independent of age, which is a major factor affecting peripheral blood MAIT cell frequencies in children (Fig. 1c and [18, 21, 22]). Moreover, sex, HLA class II genotype, BMI or level of dysglycaemia were not observed to affect MAIT cell frequencies in our study cohorts (ESM Fig. 2). Consequently, our results suggest a temporal association between circulating MAIT cell alterations and the clinical onset of type 1 diabetes. a

\begin{tabular}{|c|c|c|}
\hline $\mathrm{AAb}^{+}(\mathrm{NP})$ & $\mathrm{AAb}^{+}(\mathrm{P})$ & T1D (ND) \\
\hline \multirow[t]{5}{*}{ MAIT $\leftrightarrow$} & MAIT $\downarrow$ & MAIT $\leftrightarrow$ \\
\hline & & CD8-CD27- MAIT $\uparrow$ \\
\hline & & $\mathrm{CCR}^{+}$MAIT $\downarrow$ \\
\hline & & $\beta 7$ integrin $^{+}$MAIT $\downarrow$ \\
\hline & & $\mathrm{IFN}-\mathrm{\gamma}^{+} \mathrm{MAIT} \downarrow$ \\
\hline \multirow[t]{5}{*}{ MAIT $\downarrow[36]$} & MAIT $\leftrightarrow[36]$ & MAIT $\downarrow[35]$ \\
\hline & & $\mathrm{CCR}^{+} \mathrm{MAIT} \downarrow[35]$ \\
\hline & & CD25+ MAIT $\uparrow[35]$ \\
\hline & & $\mathrm{PD}-1^{+} \mathrm{MAIT} \uparrow[35]$ \\
\hline & & IFN- $\mathrm{Y}^{+}$MAIT $\downarrow[35]$ \\
\hline
\end{tabular}

Fig. 7 Peripheral blood MAIT cell alterations during the progression of type 1 diabetes (T1D). Alterations observed in our study in the paediatric cohort (a) and adult cohort (b) are displayed above the black line and

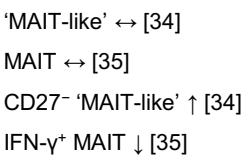

those reported in previous studies [34-36] are listed below the black line. E, established (more than 10 days after diagnosis); ND, newly diagnosed (less than 10 days after diagnosis); NP, non-progressor; P, progressor 
Of the MAIT cell alterations observed here, decreased expression of CD27 and production of IFN- $\gamma$ have also been reported by others in patients with type 1 diabetes [34, 35] (Fig. 7). Some discrepancies between our and previous studies also remain (Fig. 7). Rouxel et al [35] reported a decreased frequency of total blood MAIT cells in children with type 1 diabetes, whereas this was not observed in our study. Also, the study by Harms et al did not detect differences in the frequency of 'MAIT-like' cells in children with type 1 diabetes [34]. A more recent study by the same group reported a decreased MAIT cell frequency in $\mathrm{AAb}^{+}$at-risk individuals, especially in those who did not progress to type 1 diabetes [36], which contrasts with our finding of a decreased frequency of MAIT cells in $\mathrm{AAb}^{+}$at-risk children who progressed to type 1 diabetes. Differences in gating strategy for MAIT cells [34], as well as how stringently the study cohorts have been matched for age and HLA background, may explain some of these discrepancies. Moreover, it is important to note that several additional factors that are difficult to control for, including previous infection history, the use of corticosteroids and antibiotics, as well as the presence of other inflammatory or metabolic diseases, can affect the circulating MAIT cell compartment considerably [43]. Due to the considerable interindividual variation in peripheral blood MAIT cell frequencies (Fig. 1c), subtle alterations may also be difficult to reproducibly detect with the cohort sizes analysed in studies performed thus far.

A clear (two- to fivefold) decrease in peripheral blood MAIT cell frequencies has consistently been observed in both patients with IBD [23-26] and SLE [27, 28]. In contrast, not all studies report decreased blood MAIT frequencies in patients with multiple sclerosis $[31,44]$ and rheumatoid arthritis [30], a finding that parallels the observations made in type 1 diabetes. Therefore, it is possible that alterations in blood MAIT cells may be less prominent in organ-specific autoimmune diseases (type 1 diabetes, multiple sclerosis and rheumatoid arthritis) compared with autoimmune diseases associated with a more systemic inflammatory response (IBD and SLE). In other autoimmune diseases, the decrease of blood MAIT cells has been attributed to either a preferential homing of the cells to inflamed target tissues [23, 25-27, 29, 33] or increased apoptosis caused by the inflammatory milieu [24, 28], which both may be less prominent in type 1 diabetes.

We provide evidence that all the observed alterations in MAIT cells in children with type 1 diabetes are likely mechanistically linked together. Compared with the most abundant $\mathrm{CD} 8^{+} \mathrm{CD} 27^{+}$MAIT subpopulation, $\mathrm{CD} 8^{-} \mathrm{CD} 27^{-}$(DN) MAIT cells express less CCR5 and $\beta 7$ integrin and produce less IFN- $\gamma$ (Fig. 4). Therefore, the proportional increase of $\mathrm{CD} 8^{-} \mathrm{CD} 27^{-}$MAIT cells likely directly explains the reduced CCR 5 and $\beta 7$ integrin expression and IFN- $\gamma$ production by circulating MAIT cells from children with type 1 diabetes. Alternatively, the decrease in the expression of the homing receptors CCR5 and $\beta 7$ integrin could also be due to increased trafficking to inflamed tissues in children with type 1 diabetes, which would cause a proportional decrease in MAIT cells expressing these markers in the circulation. Interestingly, a proportional increase of blood (CD8 ${ }^{-}$) DN MAIT cells has also been reported in patients with multiple sclerosis [31]. Recent research suggests that DN MAIT cells are a functionally mature effector subpopulation of MAIT cells that, at least in vitro, appear to derive from $\mathrm{CD} 8^{+}$MAIT cells under chronic TCR stimulation [45]. Less is known about the relevance of CD27 on MAIT cell functionality. However, at least in conventional $\mathrm{T}$ cells the loss of $\mathrm{CD} 27$ is associated with a more terminal effector phenotype of $\mathrm{T}$ cells [46]. Collectively, our results therefore suggest a shift towards a more terminally differentiated MAIT phenotype in blood at the time of type 1 diabetes diagnosis.

One caveat of our study is that we could only analyse crosssectional cohorts and further work on longitudinal sample sets would be required to confirm the temporal association of peripheral blood MAIT cell alterations and the onset of type 1 diabetes. Another obvious caveat of our study is that we could only analyse MAIT cells in blood samples, where immune changes are likely to be minor compared with those in inflamed islets. In the NOD mouse model, MAIT cells accumulate in pancreatic islets during disease progression and increase their expression of IFN- $\gamma$ and granzyme B [35]. However, in the absence of MAIT cells, there is an accelerated progression to diabetes in NOD mice, suggesting that MAIT cells may actually have a protective role in type 1 diabetes, possibly due to their role in supporting gut integrity [35]. Importantly, a recent study showed that MAIT cells were completely absent in human insulitic lesions in pancreas biopsies obtained from six patients with newly diagnosed type 1 diabetes [47]. Collectively, these studies support the notion that MAIT cells may not play a direct role in the beta cell destructive process in human type 1 diabetes, but that their peripheral blood alterations rather reflect a response to the inflammatory changes during diabetes progression.

The frequencies of other circulating UCT subtypes, namely $\gamma \delta$ $\mathrm{T}$ cells and iNKT cells, were not altered either in children with newly diagnosed type 1 diabetes or $\mathrm{AAb}^{+}$at-risk children. However, in line with previous reports [21, 22, 32], the frequencies of these cell subtypes correlated with MAIT cell frequencies in blood, suggesting that MAIT cells, $\gamma \delta \mathrm{T}$ cells and iNKT cells may share common developmental and/or homeostatic factors. In contrast to earlier reports [48, 49], we did not observe a reduced frequency of NK cells in children with type 1 diabetes. No changes in the cytokine production patterns of $\gamma \delta \mathrm{T}$ cells and iNKT cells were observed, except for an increased frequency of IL$17 \mathrm{~A}^{+} \gamma \delta \mathrm{T}$ cells in children with type 1 diabetes. Interestingly, IL-17A $\mathrm{A}^{+} \gamma \delta \mathrm{T}$ cells have been demonstrated to be an important pathogenic effector cell subset in the NOD mouse model [50]. Therefore, our current observation may warrant further investigation on the role of IL-17A-producing $\gamma \delta \mathrm{T}$ cells in human type 1 diabetes. Of note, in addition to MAIT cells we also observed 
decreased expression of $\beta 7$ integrin on conventional $\mathrm{CD}^{+} \mathrm{T}$ cells in children with type 1 diabetes (Fig. 3), which to our knowledge has not been reported previously. This finding would suggest a more global defect in mucosal $\mathrm{T}$ cell homing in children with type 1 diabetes, which should also be explored in more detail in the future.

In conclusion, we present here a thorough analysis of peripheral blood MAIT cells during human type 1 diabetes development, utilising the largest and most stringently agematched cohorts analysed so far, to our knowledge. We were able to demonstrate subtle alterations in circulating MAIT cells, suggesting a shift towards a more terminally differentiated MAIT phenotype in children with newly diagnosed type 1 diabetes. We also observed a decreased frequency of MAIT cells in $\mathrm{AAb}^{+}$children who later progressed to type 1 diabetes as well as in adult type 1 diabetes patients with a short disease duration. Taken together, our current data suggest that peripheral blood MAIT cell alterations are temporally associated with the clinical onset of type 1 diabetes.

Acknowledgements The skilful technical assistance of A. Suominen (University of Turku, Finland) as well as H. Eskelinen and M. Laitinen (University of Eastern Finland) is gratefully acknowledged.

Data availability The datasets generated during the current study are available from the corresponding author upon reasonable request.

Funding Open access funding provided by University of Eastern Finland (UEF) including Kuopio University Hospital. The study was supported by the Academy of Finland (Decision number 307320), the Sigrid Jusélius Foundation and the Finnish Diabetes Research Foundation. The DIPP study was supported by the Academy of Finland (Decision numbers 250114 and 286765), the Sigrid Jusélius Foundation and JDRF (grants 1-SRA-2016-342-M-R, 1-SRA-2019-732-M).

Authors' relationships and activities The authors declare that there are no relationships or activities that might bias, or be perceived to bias, their work.

Contribution statement AMG and A-MS contributed to the acquisition and analysis of the flow-cytometric data. KN-S, RR, JP and JT contributed to the conception and design of the study and provided the clinical samples. MK and RV contributed to the conception and design of the study and were responsible for the islet autoantibody analyses. JI contributed to the conception and design of the study and was responsible for the HLA screening of the study children. AMG and TK analysed the data and drafted the manuscript. All authors revised the manuscript critically for important intellectual content and approved the final version of the manuscript. The project was conceived by TK, who is the guarantor of this work.

Open Access This article is licensed under a Creative Commons Attribution 4.0 International License, which permits use, sharing, adaptation, distribution and reproduction in any medium or format, as long as you give appropriate credit to the original author(s) and the source, provide a link to the Creative Commons licence, and indicate if changes were made. The images or other third party material in this article are included in the article's Creative Commons licence, unless indicated otherwise in a credit line to the material. If material is not included in the article's Creative Commons licence and your intended use is not permitted by statutory regulation or exceeds the permitted use, you will need to obtain permission directly from the copyright holder. To view a copy of this licence, visit http://creativecommons.org/licenses/by/4.0/.

\section{References}

1. Herold KC, Vignali DAA, Cooke A, Bluestone JA (2013) Type 1 diabetes: translating mechanistic observations into effective clinical outcomes. Nat Rev Immunol 13(4):243-256. https://doi.org/10. 1038/nri3422

2. Siljander HTA, Simell S, Hekkala A et al (2009) Predictive characteristics of diabetes-associated autoantibodies among children with HLA-conferred disease susceptibility in the general population. Diabetes 58(12):2835-2842. https://doi.org/10.2337/db081305

3. Ziegler AG, Rewers M, Simell O et al (2013) Seroconversion to multiple islet autoantibodies and risk of progression to diabetes in children. JAMA 309(23):2473-2479. https://doi.org/10.1001/jama. 2013.6285

4. Patterson CC, Dahlquist GG, Gyürüs E et al (2009) Incidence trends for childhood type 1 diabetes in Europe during 1989-2003 and predicted new cases 2005-20: a multicentre prospective registration study. Lancet 373(9680):2027-2033. https://doi.org/10. 1016/S0140-6736(09)60568-7

5. Harjutsalo V, Sjöberg L, Tuomilehto J (2008) Time trends in the incidence of type 1 diabetes in Finnish children: a cohort study. Lancet 371(9626):1777-1782. https://doi.org/10.1016/S01406736(08)60765-5

6. Barrett JC, Clayton DG, Concannon P et al (2009) Genome-wide association study and meta-analysis find that over 40 loci affect risk of type 1 diabetes. Nat Genet 41(6):703-707. https://doi.org/10. 1038/ng.381

7. Onengut-Gumuscu S, Chen W-M, Burren O et al (2015) Fine mapping of type 1 diabetes susceptibility loci and evidence for colocalization of causal variants with lymphoid gene enhancers. Nat Genet 47(4):381-386. https://doi.org/10.1038/ng.3245

8. Rewers M, Ludvigsson J (2016) Environmental risk factors for type 1 diabetes. Lancet 387(10035):2340-2348. https://doi.org/10.1016/ S0140-6736(16)30507-4

9. Murri M, Leiva I, Gomez-Zumaquero JM et al (2013) Gut microbiota in children with type 1 diabetes differs from that in healthy children: a case-control study. BMC Med 11(1):1-12. https://doi. org/10.1186/1741-7015-11-46

10. Mejía-León ME, Petrosino JF, Ajami NJ, Domínguez-Bello MG, De la Barca AMC (2014) Fecal microbiota imbalance in Mexican children with type 1 diabetes. Sci Rep 4:1-5. https://doi.org/10. 1038/srep03814

11. De Goffau MC, Fuentes S, Van Den Bogert B et al (2014) Aberrant gut microbiota composition at the onset of type 1 diabetes in young children. Diabetologia 57(8):1569-1577. https://doi.org/10.1007/ s00125-014-3274-0

12. De Groot PF, Belzer C, Aydin Ö et al (2017) Distinct fecal and oral microbiota composition in human type 1 diabetes, an observational study. PLoS One 12(12):1-14. https://doi.org/10.1371/journal. pone. 0188475

13. De Goffau MC, Luopajärvi K, Knip M et al (2013) Fecal microbiota composition differs between children with $\beta$-cell autoimmunity and those without. Diabetes 62(4):1238-1244. https://doi.org/10. 2337/db12-0526

14. Davis-Richardson AG, Ardissone AN, Dias R et al (2014) Bacteroides dorei dominates gut microbiome prior to autoimmunity in Finnish children at high risk for type 1 diabetes. Front Microbiol 5:678. https://doi.org/10.3389/fmicb.2014.00678

15. Kostic AD, Gevers D, Siljander H et al (2015) The dynamics of the human infant gut microbiome in development and in progression 
toward type 1 diabetes. Cell Host Microbe 17(2):260-273. https:// doi.org/10.1016/j.chom.2015.01.001

16. Alkanani AK, Hara N, Gottlieb PA et al (2015) Alterations in intestinal microbiota correlate with susceptibility to type 1 diabetes. Diabetes 64(10):3510-3520. https://doi.org/10.2337/db14-1847

17. Treiner E, Duban L, Bahram S et al (2003) Selection of evolutionarily conserved mucosal-associated invariant $\mathrm{T}$ cells by MR1. Nature 422(6928):164-169. https://doi.org/10.1038/nature01433

18. Koay HF, Gherardin NA, Enders A et al (2016) A three-stage intrathymic development pathway for the mucosal-associated invariant T cell lineage. Nat Immunol 17(11):1300-1311. https:// doi.org/10.1038/ni.3565

19. Godfrey DI, Uldrich AP, McCluskey J, Rossjohn J, Moody DB (2015) The burgeoning family of unconventional T cells. Nat Immunol 16(11):1114-1123. https://doi.org/10.1038/ni.3298

20. Wong EB, Ndung'u T, Kasprowicz VO (2017) The role of mucosal-associated invariant $\mathrm{T}$ cells in infectious diseases. Immunology 150(1):45-54. https://doi.org/10.1111/imm.12673

21. Gherardin NA, Souter MNT, Koay HF et al (2018) Human blood MAIT cell subsets defined using MR1 tetramers. Immunol Cell Biol 96(5):507-525. https://doi.org/10.1111/imcb.12021

22. Ben Youssef G, Tourret M, Salou M et al (2018) Ontogeny of human mucosal-associated invariant $\mathrm{T}$ cells and related $\mathrm{T}$ cell subsets. J Exp Med 215(2):459-479. https://doi.org/10.1084/jem. 20171739

23. Serriari NE, Eoche M, Lamotte L et al (2014) Innate mucosalassociated invariant T (MAIT) cells are activated in inflammatory bowel diseases. Clin Exp Immunol 176(2):266-274. https://doi. org/10.1111/cei.12277

24. Hiejima E, Kawai T, Nakase $\mathrm{H}$ et al (2015) Reduced numbers and proapoptotic features of mucosal-associated invariant $\mathrm{T}$ cells as a characteristic finding in patients with inflammatory bowel disease. Inflamm Bowel Dis 21(7):1529-1540. https://doi.org/10.1097/ MIB.0000000000000397

25. Haga K, Chiba A, Shibuya T et al (2016) MAIT cells are activated and accumulated in the inflamed mucosa of ulcerative colitis. J Gastroenterol Hepatol 31(5):965-972. https://doi.org/10.1111/jgh.13242

26. Tominaga K, Yamagiwa S, Setsu T et al (2017) Possible involvement of mucosal-associated invariant $\mathrm{T}$ cells in the progression of inflammatory bowel diseases. Biomed Res 38(2):111-121. https:// doi.org/10.2220/biomedres.38.111

27. Cho Y-N, Kee S-J, Kim T-J et al (2014) Mucosal-associated invariant $t$ cell deficiency in systemic lupus erythematosus. J Immunol 193(8):3891-3901. https://doi.org/10.4049/jimmunol.1302701

28. Chiba A, Tamura N, Yoshikiyo K et al (2017) Activation status of mucosal-associated invariant $\mathrm{T}$ cells reflects disease activity and pathology of systemic lupus erythematosus. Arthritis Res Ther 19(1):1-10. https://doi.org/10.1186/s13075-017-1257-5

29. Kim M, Yoo SJ, Kang SW, Kwon J, Choi I, Lee CH (2017) TNF $\alpha$ and IL-1 $\beta$ in the synovial fluid facilitate mucosal-associated invariant T (MAIT) cell migration. Cytokine 99:91-98. https://doi.org/ 10.1016/j.cyto.2017.07.007

30. Koppejan H, Jansen DTSL, Hameetman M, Thomas R, Toes REM, Van Gaalen FA (2019) Altered composition and phenotype of mucosal-associated invariant $\mathrm{T}$ cells in early untreated rheumatoid arthritis. Arthritis Res Ther 21(1):1-7. https://doi.org/10.1186/ s13075-018-1799-1

31. Sugimoto C, Hirotani M, Yoshikiyo K, et al (2016) The dynamics of mucosal-associated invariant $\mathrm{T}$ cells in multiple sclerosis. Springerplus 5(1):1259. https://doi.org/10.1186/ s40064-016-2923-9

32. Miyazaki Y, Miyake S, Chiba A, Lantz O, Yamamura T (2011) Mucosal-associated invariant $\mathrm{T}$ cells regulate Th1 response in multiple sclerosis. Int Immunol 23(9):529-535. https://doi.org/10. 1093/intimm/dxr047

33. Willing A, Leach OA, Ufer F et al (2014) $\mathrm{CD} 8^{+}$MAIT cells infiltrate into the CNS and alterations in their blood frequencies correlate with IL-18 serum levels in multiple sclerosis. Eur J Immunol 44(10):3119-3128. https://doi.org/10.1002/eji.201344160

34. Harms RZ, Lorenzo KM, Corley KP, Cabrera MS, Sarvetnick NE (2015) Altered $\mathrm{CD} 161^{\text {bright }} \mathrm{CD}^{+}$mucosal associated invariant $t$ (MAIT)-like cell dynamics and increased differentiation states among juvenile type 1 diabetics. PLoS One 10(1):1-21. https:// doi.org/10.1371/journal.pone.0117335

35. Rouxel O, Da Silva J, Beaudoin L et al (2017) Cytotoxic and regulatory roles of mucosal-associated invariant $\mathrm{T}$ cells in type 1 diabetes. Nat Immunol 18(12):1321-1331. https:// doi.org/10.1038/ni.3854

36. Harms RZ, Lorenzo-Arteaga KM, Ostlund KR et al (2018) Abnormal $\mathrm{T}$ cell frequencies, including cytomegalovirusassociated expansions, distinguish seroconverted subjects at risk for type 1 diabetes. Front Immunol 9:2332. https://doi.org/10. 3389/fimmu.2018.02332

37. Ilonen J, Hammais A, Laine AP et al (2013) Patterns of $\beta$-cell autoantibody appearance and genetic associations during the first years of life. Diabetes 62(10):3636-3640. https://doi.org/10.2337/ db13-0300

38. Viisanen T, Ihantola EL, Näntö-Salonen K et al (2017) Circulating $\mathrm{CXCR}^{+} \mathrm{PD}^{-} 1^{+} \mathrm{ICOS}^{+}$follicular $\mathrm{T}$ helper cells are increased close to the diagnosis of type 1 diabetes in children with multiple autoantibodies. Diabetes 66(2):437-447. https://doi.org/10.2337/db160714

39. Dias J, Sobkowiak MJ, Sandberg JK, Leeansyah E (2016) Human MAIT-cell responses to Escherichia coli: activation, cytokine production, proliferation, and cytotoxicity. J Leukoc Biol 100(1): 233-240. https://doi.org/10.1189/jlb.4ta0815-391rr

40. Brozova J, Karlova I, Novak J (2016) Analysis of the phenotype and function of the subpopulations of mucosal-associated invariant T cells. Scand J Immunol 84(4):245-251. https://doi.org/10.1111/ sji. 12467

41. Kurioka A, Jahun AS, Hannaway RF et al (2017) Shared and distinct phenotypes and functions of human $\mathrm{CD} 161^{++} \mathrm{V} \alpha 7.2^{+} \mathrm{T}$ cell subsets. Front Immunol 8:1031. https://doi.org/10.3389/ fimmu.2017.01031

42. Van Wilgenburg B, Scherwitzl I, Hutchinson EC et al (2016) MAIT cells are activated during human viral infections. Nat Commun 7: 11653. https://doi.org/10.1038/ncomms11653

43. Toubal A, Nel I, Lotersztajn S, Lehuen A (2019) Mucosalassociated invariant $\mathrm{T}$ cells and disease. Nat Rev Immunol 19: 643-657. https://doi.org/10.1038/s41577-019-0191-y

44. Salou M, Nicol B, Garcia A et al (2016) Neuropathologic, phenotypic and functional analyses of mucosal associated invariant $\mathrm{T}$ cells in multiple sclerosis. Clin Immunol 166-167:1-11. https:// doi.org/10.1016/j.clim.2016.03.014

45. Dias J, Boulouis C, Gorin JB et al (2018) The CD4 $4^{-} \mathrm{CD} 8^{-}$MAIT cell subpopulation is a functionally distinct subset developmentally related to the main $\mathrm{CD}^{+}$MAIT cell pool. Proc Natl Acad Sci U S A 115(49): E11513-E11522. https://doi.org/10.1073/pnas.1812273115

46. Larbi A, Fulop T (2014) From "truly naïve" to "exhausted senescent" T cells: When markers predict functionality. Cytom Part A 85(1):25-35. https://doi.org/10.1002/cyto.a.22351

47. Kuric E, Krogvold L, Hanssen KF, Dahl-Jørgensen K, Skog O, Korsgren O (2018) No evidence for presence of mucosalassociated invariant $\mathrm{T}$ cells in the insulitic lesions in patients recently diagnosed with type 1 diabetes. Am J Pathol 188(8):1744-1748. https://doi.org/10.1016/j.ajpath.2018.04.009 
48. Rodacki M, Svoren B, Butty V et al (2007) Altered natural killer cells in type 1 diabetic patients. Diabetes 56(1):177-185. https:// doi.org/10.2337/db06-0493

49. Qin H, Lee IF, Panagiotopoulos C et al (2011) Natural killer cells from children with type 1 diabetes have defects in NKG2Ddependent function and signaling. Diabetes 60(3):857-866. https://doi.org/10.2337/db09-1706
50. Markle JGM, Mortin-Toth S, Wong ASL, Geng L, Hayday A, Danska JS (2013) $\gamma \delta$ T cells are essential effectors of type 1 diabetes in the nonobese diabetic mouse Model. J Immunol 190(11): 5392-5401. https://doi.org/10.4049/jimmunol.1203502

Publisher's note Springer Nature remains neutral with regard to jurisdictional claims in published maps and institutional affiliations. 